
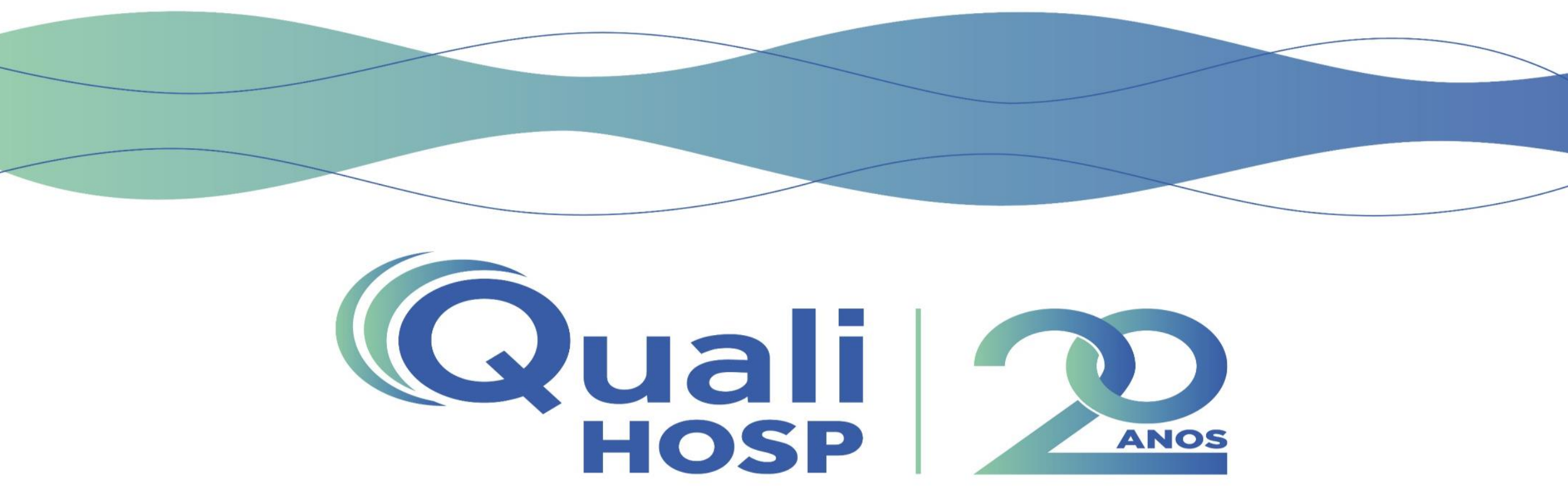

TO ERR IS HUMAN: 20 ANOS EM AÇÃO

\title{
ESTRATÉGIAS PARA CONTROLE DE BACTÉRIAS MULTIRRESISTENTES: AÇÕES EQUIPE DE ENFERMAGEM
}

Autores: Fernanda da Silva Brito; Danila de Cassia Frederico; Fernanda Barbosa de Oliveira; Fabiana Oliveira Alves 


\section{ESTRATÉGIAS PARA CONTROLE DE BACTÉRIAS MULTIRRESISTENTES: AÇÕES EQUIPE DE ENFERMAGEM.}

Introdução: O aumento de microrganismos resistentes à diversas classes de antimicrobianos tem sido progressivo nas últimas décadas, tornando-se uma ameaça à saúde pública em todo mundo. 'Dentre os microrganismos que apresentam resistência, os Enterococcos resistentes à Vancomicina (VRE) são emergentes em hospitais ao redor do mundo. Trata-se de uma bactéria que constitui parte da flora gastrointestinal e do trato genital feminino, apresenta baixa virulência e sobrevive por até 7 dias em superfícies. é importante adotarmos medidas de prevenção de colonização e infecção no âmbito hospitalar para diminuição de sua incidência

Objetivo : Avaliar o impacto das ações realizadas pela enfermagem na redução de colonização de VRE, em uma unidade de internação.

Metodologia : Estudo de coorte retrospectivo realizado em unidade de internação (de um Hospital Público de média e alta complexidade do Estado de São Paulo. Avaliados positividade de swabs de vigilância para VRE coletados no período pré-intervenção (Janeiro à Outubro de 2017) e pós- intervenção (Janeiro à Outubro de 2018) 


\section{ESTRATÉGIAS PARA CONTROLE DE BACTÉRIAS MULTIRRESISTENTES: AÇÕES EQUIPE DE ENFERMAGEM.}

\section{Ações:}

- fluxos da unidade

- Rotina coleta de swab

- Vigilância concorrente e terminal da unidade

- Higiene das mãos sensibilização de equipe e auditorias de processo

- Entrega de folder com orientações 


\section{ESTRATÉGIAS PARA CONTROLE DE BACTÉRIAS MULTIRRESISTENTES: AÇÕES EQUIPE DE ENFERMAGEM}

CONCLUSÃO: Conclui-se que ações da equipe de enfermagem, engajamento da equipe efetivo na diminuição da colonização de bactérias multirresistentes na unidade.

\section{REFERÊNCIAS}

1 Agencia Nacional de Vigilância Sanitária (ANVISA). Plano Nacional para a Prevenção e o Controle da Resistência Microbiana nos Serviços de Saúde.Brasil, Maio de 2017.

2 SOUZA, MA, RIBEIRO, LCM, PRIMO, MGB, SIRICO, SCA. Et al.Emergência e disseminação de Enterococo Resistente à Vancomicina em Hospital Universitário no Centro Oeste do Brasil. Rev. Pat. Tropical, Goiás, v.41 (2), Abr-Jun. 2012.doi: 10.5216/rpt.v41i2.19332. 